\title{
Collaborative inhibition is due to the product, not the process, of recalling in groups
}

\author{
DANIEL B. WRIGHT and ADRIANE KLUMPP \\ University of Sussex, Brighton, England
}

\begin{abstract}
When people remember together, they recall less than if they remembered separately. This is called collaborative inhibition. We examine whether this is due to the product of group recall or the process of recalling in groups. In other words, is it what the other people recall or the structure of the group dialogue that impairs group performance? Participants worked either independently or in pairs. For half of the pairs, the participants saw the items that the other person recalled. As was expected, this led to levels of recall that were lower than those for the control participants. For the other half of the pairs, the participants did not see the words recalled by the other person but still followed a turn-taking protocol. Recall was at the level of that in the nominal control condition. Collaborative inhibition is due to interference caused by the product of recall, not the process.
\end{abstract}

Remembering is often a social activity, but remembering with others can have deleterious effects (Weldon, 2001; Wittenbaum, 2003). For example, when two people have witnessed an event, if one of the people errantly recalls a detail, this error can be incorporated into the other person's memory (Gabbert, Memon, \& Allan, 2003; Wright, Self, \& Justice, 2000). Even accurate recall can have negative effects. If a group of people are given a set of stimuli to remember and later are asked to recall them, they tend to recall less than the same number of people recalling individually. This is called collaborative inhibition (Weldon \& Bellinger, 1997) and has been shown in several papers for free recall (e.g., Andersson \& Rönnberg, 1995, 1996; Meudell, Hitch, \& Boyle, 1995; Weldon, Blair, \& Huebsch, 2000; see Thompson, 2002, for a review). Consider the following example. Suppose that two people, together, recall six stimuli (bread, coffee, bacon, eggs, tea, and cereal) and are compared with individuals recalling separately. Suppose that one individual recalls five items (bread, sausage, coffee, bacon, and eggs) and another individual recalls five items (bread, bacon, tea, cereal, and toast). Together this pair recalls eight unique items (bread, sausage, coffee, bacon, eggs, tea, cereal, and toast). Thus, although the pair recalling together recalls more than either individual, the pair recalls less than the total for the individuals, if their nonredundant items are pooled together. The detriment involved in working in groups also has been found in other areas of psychology-for example, with problem solving tasks (Paulus, Dugosh, Dzindolct, Coskun, \& Putman, 2002) and with helping behavior (Latané \& Nida, 1981).

Correspondence concerning this article should be addressed to D. B. Wright, Psychology Department, University of Sussex, Brighton BN1 9QH, England (e-mail: danw@sussex.ac.uk).
We will consider two explanations for collaborative inhibition. The first is that the product of the recallhearing somebody else recall the word bread-impairs memory performance. This may occur because increased activation of bread inhibits memory for other words (Anderson \& Spellman, 1995) or because hearing bread disrupts the most natural recall strategy for the other words (D. R. Basden \& B. H. Basden, 1995). The second explanation is that the process of recalling in groups creates the detriment. It could do this in a number of ways. For example, the turn-taking etiquette of most group discussions means that you are not able to choose your own timing for retrieving items. There are also various motivational factors that might influence group discussions.

The social psychologists studying group problemsolving tasks (i.e., brainstorming) often describe how group processes may impair performance. In a particularly relevant study, Diehl and Stroebe (1987) compared brainstorming for four-person groups between conditions in which they controlled the turn-taking element and conditions in which the participants could not hear the other people's ideas. They found that it was the turntaking process that impaired group performance, rather than actually hearing the other people's ideas. This impairment continues to be observed in much social psychology (e.g., Nijstad, Stroebe, \& Lodewijkx, 2003). However, brainstorming is a different task from memory recall and may be more affected by social processes such as fear of negative evaluation, social loafing, and so forth. Weldon et al. (2000) conducted a series of experiments to investigate the role of some social processes in collaborative inhibition. Their experiments all had a similar structure, which involved seeing whether a manipulation designed to lessen the impact of different motivational factors (e.g., offering a monetary incentive or making the group feel more cohesive) affected the level 
of collaborative inhibition. None of the manipulations affected this level. This appears to run counter to Diehl and Stroebe's findings, which would mean that brainstorming is affected by the processes involved in dialogue but memory recall is not. Although this is possible, there were some important differences between the studies. Weldon et al.'s studies could be criticized by arguing that the manipulations may not have been strong enough to eliminate the effect or that there are a host of motivational factors, any of which can produce collaborative inhibition, and eliminating any one of them is insufficient to prevent collaborative inhibition. More important for the present purposes is that whereas Weldon et al. focused on motivation factors, Diehl and Stroebe focused on the turn-taking process involved in much communication. Here, we tested whether this turn-taking process affects memory collaboration.

The present study was designed to compare a control condition in which people recalled individually with two collaborative group conditions. In one, the people in the pairs took turns recalling items from a previously studied list. This is the standard memory collaboration condition, in which each participant learns what the other is recalling. Both the product of the recall and the process of the turn-taking dialogue can affect performance. In a second collaborative group condition, the participants again took turns recalling the previously seen list, but neither knew which items the other person had recalled. People in this condition can be affected only by the process of recalling in groups, not by the product of what the other person recalls.

In past collaboration research, the group conditions have been compared with nominal sets of individuals. The people in the control condition have arbitrarily been assigned to specific nominal groups. The arbitrary nature of assigning people to nominal groups is an additional source of error, can lead to erroneous findings, and is unnecessary. Rather than arbitrarily assigning participants to nominal groups on the basis of where their data lay in the data set or when they took part in the study, we used an algorithm that estimated various statistics for all possible sets of pairs (Wright, 2004). As is the norm in group memory studies, only nonredundant items were counted for any individual pair of people.

\section{METHOD}

Sixty people volunteered to take part in the experiment. Most of the participants were students at the University of Sussex; others were employed in different occupations (age range, 20-50 years; mean, 26 years). All the participants were naive as to the experimental hypothesis.

Four lists of words from Stadler, Roediger, and McDermott's (1999) corpus of semantic associates were used: bread, man, music, and sleep. These four words were not presented during the study phase but were provided on the recall sheet to provide a label for each list. Although the original lists comprised 15 items, these lists were shortened to 12 items for the present study.

The participants were randomly assigned to one of three conditions, with the restriction that there were 20 people in each condition. The experimenter was present throughout the testing. In the nominal condition, the participants worked alone to recall the words. In the collaborative group see condition, the participants worked together in pairs, took turns recalling the words, and showed each other the words as they were being recalled. The recall list was visible throughout the group recall period. The participants in the collaborative group not see condition also recalled word lists in pairs, using a turn-taking method; however, they did not see which items the other person recalled. It is worth noting that group size is related to collaborative inhibition (B. H. Basden, D. R. Basden, \& Henry, 2000), so using 2-person groups meant that we would not be expecting a large collaborative inhibition effect.

The participants in the nominal group were tested individually; those in the collaborative groups sat opposite each other at a table. The participants were told that they were going to see word lists and later would be tested on these lists, but they were not told how they would be tested. They were told not to talk or write down items during the study period. Each participant was presented with a booklet containing the word lists. Each word was presented on a separate sheet of paper, displayed in the center and printed in 20-point bold black font. The participants were instructed to start on the first page, study the presented word for $4 \mathrm{sec}$, turn the page, study the second word, and so on until all the words had been studied. After all the items had been studied, the participants completed simple addition problems for $60 \mathrm{sec}$ to reduce recency effects.

The distractor task was followed by a written free recall test. Those assigned to the nominal group were instructed to write down as many items as they could remember from the word lists. List names (bread, man, music, and sleep) were provided at the top of the recall sheet. The participants were told that they could recall the studied items in any order, starting with any of the lists, and that they could switch between lists. There was no time limit for recalling the studied items, but the participants were told that the recall period would end if they failed to recall an additional word within $30 \mathrm{sec}$. Total recall times were not recorded.

In the see condition, the pairs were given a single answer sheet displaying list labels at the top, and they were instructed to work together to recall items from the studied word lists. One member of the pair was chosen, at random, to begin the recall phase by writing down one of the studied items. The paper was then passed to the other person, who would write down an item. They were told not to write a word that had already been recalled by either person. This turn-taking procedure was repeated until 1 person failed to recall a new item within $10 \mathrm{sec}$. The recall sheet would be handed back to the other group member. If a participant failed to recall another item within $10 \mathrm{sec}$ for the third time, this participant was excluded from further recall, and the other person was given the chance to recall the remaining items.

The not see condition followed the same procedure as the see condition, except that each person had his or her own recall sheet. When a person finished writing down an item, he or she told the other person to start. A 30-cm barrier was placed between the participants so that they could not see each other's answer sheets. The participants were instructed not to discuss the items with each other, and the experimenter was present to make sure that this did not happen. At no point in the study were the participants shown the words recalled by the other person.

Following the first free recall, all the participants completed a final individual written recall test. The participants formerly in the collaborating conditions completed the second recall immediately after the first recall. The participants formerly in the individual recall condition were required to complete another short distractor task for approximately $30 \mathrm{sec}$ (pilot research showed that the recall phase in the nominal conditions was shorter than that in the collaborating conditions). As in the first recall, the participants were presented with an answer sheet displaying category names at the top and were instructed to write down as many words as they could remember, in any order. No time limit was set for the final recall test. When the participants could no longer remember any items, they were debriefed and thanked for their participation. 


\section{RESULTS}

The participants, whether recalling individually or in pairs, could recall a maximum of 48 words. The 20 people recalling individually reported, on average, 19.8 words, or $41 \%$. Traditionally, researchers have constructed nominal groups by randomly assigning people into pairs. With 20 participants, there are over 600 million possible ways that this can be done, and the choice can affect the results (the number of permissible pairs is: $(n-1)(n-3) \ldots[n-$ $(n-1)]$, see Wright, 2004). The alternative used here involved calculating the mean of all these sets of pairs, which was 30.14 words $(63 \%)$. The mean for the pairs of people in the see condition was 22.70 words $(47 \%)$. Recall for people in the not see condition was calculated by counting the number of nonredundant words for each pair. The mean was 28.70 words $(60 \%)$. Figure 1 shows these data and their standard errors. The standard error for the nominal condition was calculated using the ngallpairs function from Wright (2004; the author's Web site), with the bias correction applied.

The two comparisons of interest are whether the not see condition differs from either the see condition or the nominal control condition. Participants in the not see condition recalled significantly more words than did participants in the see condition did [difference, 6.0 words; $t(18)=2.19, p=.04$ ], showing that knowing the actual words being recalled was detrimental to the amount recalled. The results for the not see group did not differ significantly from the nominal group estimates [1.4 words; $t(14)=0.65, p=.53$, using the Welch-Satterthwaite approximation for the degrees of freedom]. Thus, there was no evidence that the not see condition differed from the nominal condition. It is also worth reporting that the participants in the see condition did recall less than the nominal group did $[t(14)=3.46, p=.004]$, showing that collaborative inhibition was observed. That collaborative inhibition is not always observed with 2-person groups may be due to the arbitrary way in which nominal groups have been created in previous studies.

All the participants recalled individually during the second phase of the study. They had similar levels of free recall: 19.85 (41\%) for individuals, 19.25 (40\%) for the see pairs, and $19.75(41 \%)$ for the not see pairs $[F(2,57)<1]$. None of the pairwise comparisons approached significance.

\section{DISCUSSION}

Collaborative inhibition is the scientific phrase for the old adage that "too many cooks spoil the broth." As in a kitchen cluttered with too many chefs, the finding that people in groups recall less than people individually do shows that something about group recall is detrimental. Here, we asked whether it is the product of the recall or the process of recalling that creates collaborative inhibition. In the standard collaborative inhibition study, a control group is compared with a collaboration group where both the product and the process of recall can interfere with performance. The unique aspect of the present study is a condition, not see, that includes the procedural aspects of the standard collaboration condition, but without allowing the product of the recall to interfere. If performance in this condition was like that in the standard collaboration condition, the product of the other person's recall could not be responsible for collaborative inhibition. However, if performance was like that in the nominal condition, it could be argued that it is the product that creates, to a large extent, collaborative inhibition.

The findings are summarized in Figure 1. Performance in the not see condition was at a level similar to that in the nominal condition and was significantly different from that in the see condition. This provides support for the explanation according to which the product of the recall interferes with the other person's recall, rather than the process of recalling. This differs from the finding from creative problem solving, where the response process did affect the number of ideas (Diehl \& Stroebe, 1987; Nijstad et al., 2003), but it is likely that some of the social and motivational processes involved with brainstorming are less important in memory recall.

There are two mechanisms by which the product of recall can interfere. B. H. Basden, D. R. Basden, Bryner, and Thomas (1997) argued that collaborative inhibition is due to the same mechanisms as part-list cuing inhibition: Providing part of a recall list to participants can force them to adopt alternative response strategies. These alternative response strategies may not be as good as the one the participant planned on using. A second mechanism is retrieval-induced forgetting. It may also be that the meaning of the words makes other, associated words less accessible. Anderson and Spellman (1995) have shown that retrieving words can make memories for related words less accessible. However, this does not appear to occur when people are presented just with words

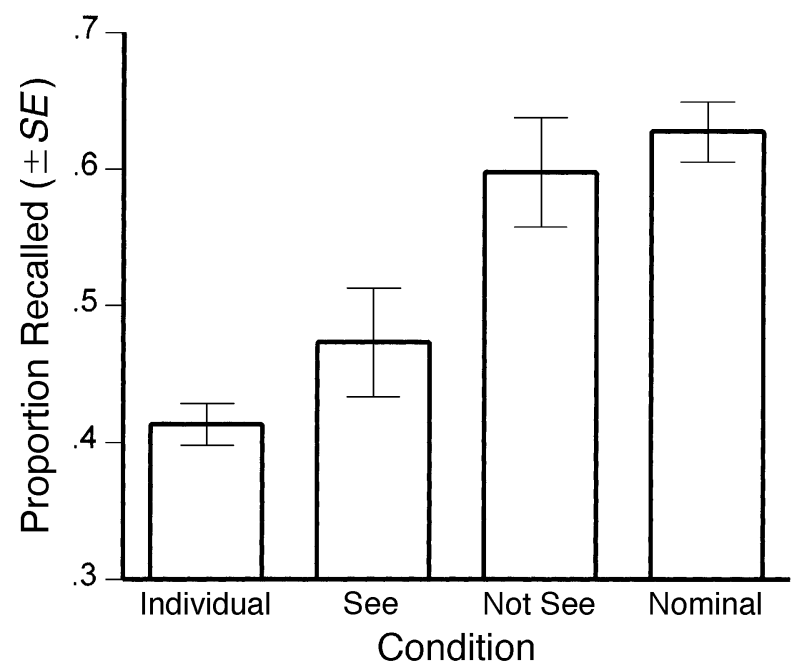

Figure 1. The mean number of items recalled by individuals and by participants in the see and the not see conditions and the estimates for nominal groups based on the participants who recalled individually. Bars represent standard errors. 
(Anderson, Bjork, \& Bjork, 2000). Further investigations into how words interfere are warranted.

In summary, the present study confirmed that collaborative inhibition can occur in 2-person collaborating groups. However, the effect disappears when each participant does not see what the other person recalls.

\section{REFERENCES}

Anderson, M. C., BJork, E. L., \& BJork, R. A. (2000). Retrieval-induced forgetting: Evidence for a recall-specific mechanism. Psychonomic Bulletin \& Review, 7, 522-530.

ANDERSON, M. C., \& Spellman, B. A. (1995). On the status of inhibitory mechanisms in cognition: Memory retrieval as a model case. Psychological Review, 102, 68-100.

ANDERSSON, J., \& RöNNBERG, J. (1995). Recall suffers from collaboration: Joint recall effects of friendship and task complexity. Applied Cognitive Psychology, 9, 199-211.

ANDERSSON, J., \& RöNNBERG, J. (1996). Collaboration and memory: Effects of dyadic retrieval on different memory tasks. Applied Cognitive Psychology, 10, 171-181.

BASDEN, B. H., BASDEN, D. R., BRYNer, S., \& Thomas, R. L., III (1997). A comparison of group and individual remembering: Does collaboration disrupt retrieval strategies? Journal of Experimental Psychology: Learning, Memory, \& Cognition, 23, 1176-1189.

BASDEN, B. H., BASDEN, D. R., \& HENRY, S. (2000). Costs and benefits of collaborative remembering. Applied Cognitive Psychology, 14, 497-507.

BASDEN, D. R., \& BASDEN, B. H. (1995). Part-list cuing inhibition as retrieval strategy disruption. Journal of Experimental Psychology: Learning, Memory, \& Cognition, 21, 1659-1672.

Diehl, M., \& Stroebe, W. (1987). Productivity loss in brainstorming groups: Toward the solution of a riddle. Journal of Personality \& Social Psychology, 53, 497-509.

Gabbert, F., Memon, A., \& Allan, K. (2003). Memory conformity: Can eyewitnesses influence each other's memories for an event? $A p$ plied Cognitive Psychology, 17, 533-543.
LATANÉ, B., \& NidA, S. (1981). Ten years of research on group-size and helping. Psychological Bulletin, 89, 308-324.

Meudell, P. R., Hitch, G. J., \& BoYle, M. M. (1995). Collaboration in recall: Do pairs of people cross cue each other to produce new memories? Quarterly Journal of Experimental Psychology, 48A, 141-152.

Nisstad, B. A., Stroebe, W., \& Lodewijkx, H. F. M. (2003). Production blocking and idea generation: Does blocking interfere with cognitive processes? Journal of Experimental Social Psychology, 39, 531-548.

Paulus, P. B., Dugosh, K. L., Dzindolet, M. T., Coskun, H., \& PutMAN, V. L. (2002). Social and cognitive influences in group brainstorming: Predicting production gains and losses. European Review of Social Psychology, 12, 299-325.

Stadler, M. A., Roediger, H. L., III, \& McDermott, K. B. (1999). Norms for word lists that create false memories. Memory \& Cognition, 27, 494-500.

THOMPSON, R. (2002). Are two heads better than one? The Psychologist, 15, 616-619.

WeLDON, M. S. (2001). Remembering as a social process. In D. L. Medin (Ed.), The psychology of learning and motivation: Advances in research and theory (Vol. 40, pp. 67-120). San Diego: Academic Press.

Weldon, M. S., \& Bellinger, K. D. (1997). Collective memory: Collaborative and individual processes in remembering. Journal of Experimental Psychology: Learning, Memory, \& Cognition, 23, 1160-1175.

Weldon, M. S., BlaIR, C., \& HuebSCH, P. D. (2000). Group remembering: Does social loafing underlie collaborative inhibition? Journal of Experimental Psychology: Learning, Memory, \& Cognition, 26, 15681577.

Wittenbaum, G. M. (2003). Putting communication into the study of group memory. Human Communication Research, 29, 616-623.

Wright, D. B. (2004). Calculating nominal group statistics in collaboration research. Manuscript under review.

Wright, D. B., Self, G., \& Justice, C. (2000). Memory conformity: Exploring misinformation effects when presented by another person. British Journal of Psychology, 91, 189-202.

(Manuscript received November 4, 2003; revision accepted for publication March 1, 2004.) 